\title{
Adaptive thermostability of light-harvesting complexes in marine picocyanobacteria
}

\author{
Justine Pittera ${ }^{1,2}$, Frédéric Partensky ${ }^{1,2}$ and Christophe Six ${ }^{1,2}$ \\ ${ }^{1}$ Sorbonne Universités, Université Pierre and Marie Curie (Paris 06), UMR 7144, Marine Phototrophic \\ Prokaryotes (MaPP) Team, Roscoff Cedex 29688, France and ${ }^{2}$ Centre National de la Recherche Scientifique, \\ UMR 7144, Marine Plankton Group, Station Biologique, Roscoff Cedex, France
}

\begin{abstract}
Marine Synechococcus play a key role in global oceanic primary productivity. Their wide latitudinal distribution has been attributed to the occurrence of lineages adapted to distinct thermal niches, but the physiological and molecular bases of this ecotypic differentiation remain largely unknown. By comparing six strains isolated from different latitudes, we showed that the thermostability of their light-harvesting complexes, called phycobilisomes (PBS), varied according to the average sea surface temperature at strain isolation site. Comparative analyses of thermal unfolding curves of the three phycobiliproteins (PBP) constituting PBS rods suggested that the differences in thermostability observed on whole PBSs relied on the distinct molecular flexibility and stability of their individual components. Phycocyanin was the least thermostable of all rod PBP, constituting a fragility point of the PBS under heat stress. Amino-acid composition analyses and structural homology modeling notably revealed the occurrence of two amino-acid substitutions, which might have a role in the observed differential thermotolerance of this phycobiliprotein among temperature ecotypes. We hypothesize that marine Synechococcus ancestors occurred first in warm niches and that during the colonization of cold, high latitude thermal niches, their descendants have increased the molecular flexibility of PBP to maintain optimal light absorption capacities, this phenomenon likely resulting in a decreased stability of these proteins. This apparent thermoadaptability of marine Synechococcus has most probably contributed to the remarkable ubiquity of these picocyanobacteria in the ocean. The ISME Journal (2017) 11, 112-124; doi:10.1038/ismej.2016.102; published online 26 July 2016
\end{abstract}

\section{Introduction}

Temperature is an environmental factor that greatly impacts the distribution of living forms on our planet. Temperature varies widely over the course of the day, seasons as well as across latitudes and therefore constitutes a major ecological constraint on the physiology of organisms and hence on the functioning of ecosystems. In particular, temperature is one of the main factors controlling inorganic carbon fixation, a process which in the oceans is prevalently ensured by phytoplanktonic cells (Falkowski, 1994; Behrenfeld et al., 2006). Among these, Prochlorococcus and Synechococcus, two highly abundant picocyanobacteria $(<2 \mu \mathrm{m})$, are thought to be responsible for up to $25 \%$ of the global net oceanic primary production (Partensky et al., 1999; Flombaum et al., 2013). Whereas Prochlorococcus is restricted to the $40{ }^{\circ} \mathrm{S}-45^{\circ} \mathrm{N}$ latitudinal band, Synechococcus occurs from the equator to polar circles (Neuer, 1992; Zwirglmaier et al., 2008;

Correspondence: C Six, UMR 7144 UPMC-CNRS, Station Biologique de Roscoff, CS 90074, 29688 Roscoff, France.

E-mail: christophe.six@sb-roscoff.fr

Received 21 December 2015; revised 21 April 2016; accepted 24 April 2016; published online 26 July 2016
Huang et al., 2012), suggesting that this ubiquitous picocyanobacterium has developed efficient adaptive strategies to cope with natural temperature variations (Mackey et al., 2013; Pittera et al., 2014).

Phylogenetic studies using various markers have evidenced the large genetic microdiversity occurring within the Synechococcus genus (Fuller et al., 2003; Ahlgren and Rocap, 2012). For instance, based on the high-resolution petB marker, 15 clades and 28 subclades (Mazard et al., 2012) have been delineated within the main radiation, called subcluster 5.1 (Herdman et al., 2001). Basin-scale phylogeographical studies have shown that the most prevalent marine Synechococcus lineages, that is, clades I-IV, occupy distinct ecological niches (Zwirglmaier et al., 2008; Sohm et al., 2015). Clades I and IV are confined to nutrient-rich, cold or temperate waters at high latitude $\left(>30^{\circ} \mathrm{N} / \mathrm{S}\right)$, whereas clades II and III preferentially thrive in warm waters, with the former being prevalent in subtropical and tropical open ocean and the latter dominating in the eastern Mediterranean Sea (Mella-Flores et al., 2011; Sohm et al., 2015; Farrant et al., 2016).

Pittera et al. (2014) have evidenced a correspondence between the thermophysiology of Synechococcus clades I and II and their respective thermal niches. Indeed, members of these lineages were 
shown to exhibit thermal preferenda (that is, temperature growth ranges and growth maxima) consistent with the seawater temperature at their isolation site, as well as a differential sensitivity to thermal stress. These genetically defined lineages, physiologically adapted to specific thermal niches, therefore correspond to different 'temperature ecotypes' (or 'thermotypes'), a concept previously defined for Prochlorococcus clades HLI and HLII, which preferentially thrive in cool temperate waters and warm subtropical waters, respectively, a discrepancy also explained by the distinct growth temperature characteristics of representative isolates (Johnson et al., 2006; Zinser et al., 2007). Although other factors such as the macronutrients can be important sources of diversification within the marine Synechococcus radiation, recent field studies have demonstrated that temperature is one of the main factors explaining the variability of the genotypic composition of marine Synechococcus assemblages, with different thermotypes forming well-defined populations in distinct latitudinal bands at oceanic basin scales (Sohm et al., 2015; Farrant et al., 2016).

Pittera et al. (2014) also showed that during thermal stress experiments the capacity of the temperature ecotypes to acclimate and endure temperature variations notably relies on their ability to optimize the functionality of their photosystem II (PS-II) at different temperatures. This macromolecular complex is indeed known to be a particularly temperature responsive component of the photosynthetic machinery (Murata et al., 2007). Like in red algae, the major PS-II light-harvesting antenna of Synechococcus is a giant, water soluble pigmentprotein complex, the phycobilisome (PBS). This macrocomplex, composed of a central core surrounded by six rods, is made of phycobiliproteins (PBP), themselves composed of two subunits ( $\alpha$ and $\beta$ ) aggregated as hexameric discs $(\alpha \beta)_{6}$. Different openchain tetrapyrrolic chromophores, the phycobilins, are bound to the apoproteins by thioether bonds on cystein residues, and absorb at specific wavelength bands (Glazer, 1985; Glazer, 1989; Sidler, 1994; Six et al., 2007b). Based on their amino-acid sequence and absorption properties, the PBPs have been assigned to distinct classes. The PBS core is always made of allophycocyanin, which binds the blue chromophore phycocyanobilin (PCB, $\mathrm{A}_{\max } \sim 620 \mathrm{~nm}$ ). In marine Synechococcus, the basal part of PBS rods is composed of phycocyanin (PC) that most often binds PCB and phycoerythrobilin (PEB, $\mathrm{A}_{\max }$ $\sim 550 \mathrm{~nm}$ ), usually at a molar ratio of 1:2 (Ong and Glazer 1987; Six et al., 2007b; but see also Blot et al., 2009). The distal part of the rods is generally made of two types of phycoerythrins, PE-I and PE-II, which display different combinations of PEB and phycourobilin (PUB, $\mathrm{A}_{\max } \sim 495 \mathrm{~nm}$ ), depending on the strain (Ong and Glazer, 1991; Sidler, 1994; Humily et al., 2013). The whole PBS structure is further stabilized by a set of linker polypeptides
(Glazer, 1984). The design of the complex induces a directional transfer of excitation energy from the rod periphery to the PBS core and in fine to reaction centers (Glazer, 1989). The efficiency of the energy transfer in the PBS may depend on environmental factors, such as incident photon flux or osmotic pressure, and can be monitored by measuring energy leaks, emitted as fluorescence, for each PBP (see, for example, Ke, 2001; Six et al., 2007a; Kupper et al., 2009).

As the PBS constitutes the main entrance gate of light energy into the photosynthetic machinery, the sustainability of the PBP function is of crucial importance for the cell. In all PBPs, the native protein molecular environment constrains the phycobilins to a planar conformation that allows maximal light absorption (Scheer and Kufer, 1977; MacColl et al., 1980; Glazer, 1985). In disordered proteins, the bilin conformation is no more constrained by the protein environment and tends to adopt a more cyclic conformation, inducing lower visible light but higher ultraviolet absorbance. Temperature is well known to influence protein conformation and is therefore likely to affect the function of cofactors such as phycobilins (Bowen et al., 2000). Consequently, during evolution, different variants of a protein have evolved, with cold environment selecting for more flexible proteins at the cost of thermostability, whereas warm environments favor stability at the cost of psychroflexibility (Jaenicke and Böhm, 1998; Szilagyi and Zavodszky, 2000).

Here, we combined different approaches to compare the functional thermostability and molecular flexibility of the photosynthetic antennae of six marine Synechococcus strains representative of different thermotypes and unveiled some of the molecular bases of this adaptation to temperature.

\section{Materials and methods}

\section{Biological material and growth conditions}

We selected six marine strains isolated at a similar distance from the coast (mesotrophic waters), along a latitudinal gradient of temperature (Figure 1, Table 1). The six strains belong to the same PEB-rich pigment type (3a sensu Six et al., 2007b) and have therefore a similar PBS structure and composition. Clonal Synechococcus strains M16.1, RS9907, WH7803, ROS8604, MVIR-16-2 and MVIR-18-1 (http://roscoff-culture-collection. org/) were grown in PCR-S11 culture medium (Rippka et al., 2000) supplemented with $1 \mathrm{~mm}$ sodium nitrate, under $80 \mu \mathrm{mol}$ photons $\mathrm{m}^{-2} \mathrm{~s}^{-1}$ white light irradiance provided by fluorescent tubes (Sylvania Daylight F18W/54-765 T8). Cultures were acclimated for at least four weeks to a range of temperature $\left(9-35^{\circ} \mathrm{C}\right)$ using temperaturecontrolled growth chambers. 


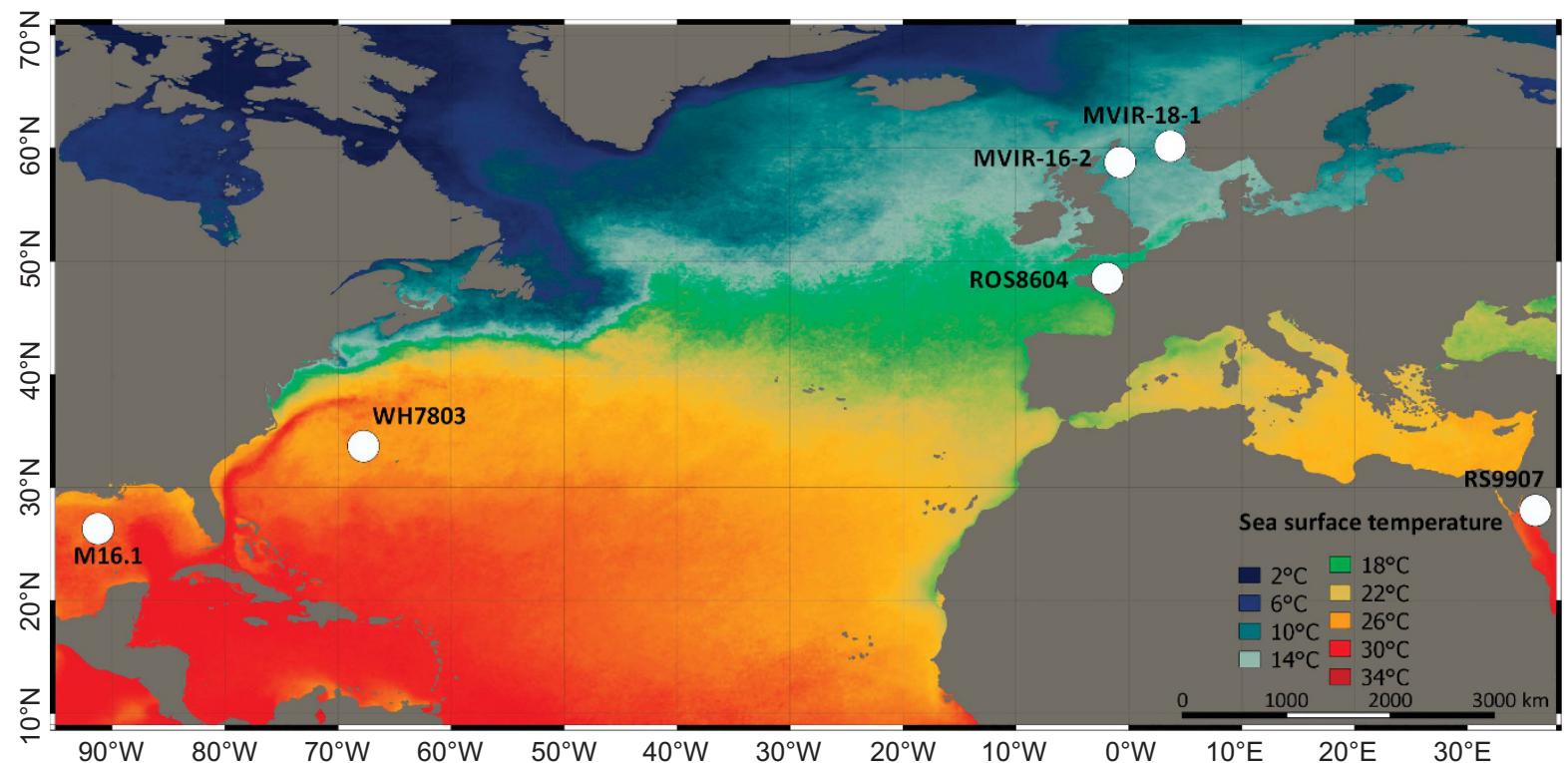

Figure 1 Isolation sites of the six marine Synechococcus strains used in this study. Colors indicate the mean average annual sea surface temperature (MODIS) over the 2004-2014 period (QGIS 2.10.1).

Table 1 Isolation characteristics and growth temperature properties of the six marine Synechococcus strains used in this study

\begin{tabular}{|c|c|c|c|c|c|c|}
\hline Strain name & RS9907 & M16.1 & WH7803 & ROS8604 & MVIR-16-2 & MVIR-18-1 \\
\hline RCC strain number & 2382 & 791 & 752 & 2380 & 1594 & 1682 \\
\hline Phylogenetic clade ${ }^{a}$ & II & II & $\mathrm{V}$ & I & I & I \\
\hline \multirow[t]{2}{*}{ Isolation area } & Red Sea & Gulf of Mexico & Sargasso Sea & English & Southern & Southern \\
\hline & & & & Channel & Norway Sea & Norway Sea \\
\hline Isolation latitude & $29^{\circ} 28^{\prime} \mathrm{N}$ & $27^{\circ} 42^{\prime} \mathrm{N}$ & $33^{\circ} 45^{\prime} \mathrm{N}$ & $48^{\circ} 43^{\prime} \mathrm{N}$ & $60^{\circ} 19^{\prime} \mathrm{N}$ & $61^{\circ} 00^{\prime} \mathrm{N}$ \\
\hline Isolation longitude & $34^{\circ} 55^{\prime} \mathrm{E}$ & $91^{\circ} 18^{\prime} \mathrm{W}$ & $67^{\circ} 30^{\prime} \mathrm{W}$ & $3^{\circ} 59^{\prime} \mathrm{W}$ & $3^{\circ} 29^{\prime} \mathrm{W}$ & $1^{\circ} 59^{\prime} \mathrm{E}$ \\
\hline Mean annual water temperature $\left({ }^{\circ} \mathrm{C}\right)^{\mathrm{b}}$ & $24.1 \pm 0.6$ & $25.8 \pm 0.3$ & $22.7 \pm 0.2$ & $13.6 \pm 0.3$ & $10.3 \pm 0.2$ & $10.2 \pm 0.2$ \\
\hline Annual water temperature amplitude $\left({ }^{\circ} \mathrm{C}\right)^{\mathrm{b}}$ & $5.5 \pm 0.7$ & $6.9 \pm 0.9$ & $5.9 \pm 0.5$ & $5.3 \pm 0.6$ & $3.1 \pm 0.4$ & $4.4 \pm 0.4$ \\
\hline Temperature range for growth $\left({ }^{\circ} \mathrm{C}\right)$ & $18->35^{\mathrm{c}}$ & $18->35^{\mathrm{d}}$ & $16-34^{\mathrm{d}}$ & $16-30^{\mathrm{d}}$ & $<12-25^{\mathrm{d}}$ & $<9-25^{\mathrm{d}}$ \\
\hline Optimal growth temperature $\left({ }^{\circ} \mathrm{C}\right)$ & $30-32^{\mathrm{c}}$ & $32^{\mathrm{d}}$ & $33^{\mathrm{d}}$ & $26^{\mathrm{d}}$ & $22^{\mathrm{d}}$ & $22^{\mathrm{d}}$ \\
\hline
\end{tabular}

For more details, see the Roscoff Culture Collection (RCC) website.

${ }^{a}$ According to Fuller et al. (2003), Mazard et al. (2012) and Pittera et al. (2014).

${ }^{\mathrm{b}}$ Average temperature and temperature amplitude at the strain isolation sites (resolution: $5 \times 5^{\circ}$ squares) over the $2004-2014$ period, as derived from satellite data from the National Oceanic and Atmospheric Administration (NOAA).

cThis study.

${ }^{\mathrm{d}}$ According to Pittera et al. (2014).

In vivo fluorescence emission in response to increasing temperature

Synechococcus cultures in mid exponential growth phase were placed in a temperature-controlled water bath at growth temperature in the dark. Temperature was then progressively increased by $3^{\circ} \mathrm{C}$ steps of $10 \mathrm{~min}$, up to $46^{\circ} \mathrm{C}$. At the end of each temperature level, an in vivo fluorescence emission spectrum was recorded upon excitation at $530 \mathrm{~nm}$ using a LS-50B spectrofluorimeter (Perkin Elmer, Waltham, MA, USA). The energy transfer between the PBPs was assessed by measuring their relative fluorescence emission levels, as increases in the relative heights of the PC or PE emission peaks are indicative of energy leaks. The PE to PC fluorescence emission ratio was then calculated, log-transformed and plotted against instantaneous temperature by homology with the well-known Arrhenius-breaking temperature plots, allowing us to determine the PBS breaking temperature ( $T_{\mathrm{PBS}}$; Dahlhoff et al., 1991; Stillman and Somero, 1996); Supplementary Figure S1). For further analyses, the fluorescence emission spectra were decomposed using the a leultraviolet-Vis-IR Spectral software 2.0 (www.fluor tools.com).

\section{Phycobiliprotein denaturation curves}

Phycobiliprotein purification was carried out using sucrose gradients and isoelectric focusing, as previously described (Six et al., 2005). PBP structural thermostability was assessed by monitoring 
phycobilin absorbance and fluorescence along protein thermal unfolding curves (Grimsley et al., 2013), from $30^{\circ} \mathrm{C}$ to $85^{\circ} \mathrm{C}$, with PBP solutions at $\sim 30 \mathrm{~nm}$ for PEs $\left(2.15 \times 10^{6} \mathrm{M}^{-1} \mathrm{~cm}^{-1}\right.$ and $2.41 \times 10^{6} \mathrm{M}^{-1} \mathrm{~cm}^{-1}$ at $545 \mathrm{~nm}$ for PE-II and PE-I, respectively; Glazer and Hixson, 1977; Wyman 1992) and $100 \mathrm{~nm}$ for PC $\left(2 \times 10^{5} \mathrm{M}^{-1} \mathrm{~cm}^{-1}\right.$ at $620 \mathrm{~nm}$ as estimated from Glazer et al., 1973 and Glazer and Hixson, 1975). Absorption and fluorescence emission spectra were recorded during a progressive temperature increase, performed by $5{ }^{\circ} \mathrm{C}$ steps of $5 \mathrm{~min}$ each. The fluorescence emission spectra were recorded upon excitation at $545 \mathrm{~nm}$ for PE and $620 \mathrm{~nm}$ for PC and the absorbance was monitored at the wavelength of the acceptor phycobilins, that is PEB in PEs $(\sim 545 \mathrm{~nm})$ and PCB in PCs $(\sim 620 \mathrm{~nm}$; Sidler, 1994). For each PBP, the absorbance values were plotted against instantaneous temperature and fitted with a sigmoid curve using the following equation:

$y=\mathrm{b}+\frac{a-\mathrm{b}}{1+10^{\left(\log _{50 \%}\right) \mathrm{s}}}$

where $a$ is the initial maximal absorption, $b$ the absorption minimum at $85^{\circ} \mathrm{C}$ and $s$ the Hill slope of the function. The mid-unfolding temperature $\mathrm{T}_{50 \%}$, that is, the temperature at which the protein has lost half of its absorption capacities, which is related to the molecular flexibility of the protein, was determined using the SigmaPlot v10 software (Supplementary Figures S2 and S3).

Analysis of phycobiliprotein sequences and homology modeling

Using GenBank and the Cyanorak information system (http://application.sb-roscoff.fr/cyanorak/), we compiled a database encompassing the sequences of the two subunits of $21 \mathrm{PC}, 21 \mathrm{PE}-\mathrm{I}$ and 20 PE-II. Unpublished sequences were deposited in GenBank nucleotide sequence database under accession numbers mentioned in Supplementary Table S1. All sequences were aligned using Bioedit 7.2.3 (Hall, 1999) and the distributions and amino-acid frequencies of PC (RpcA and RpcB), PE-I (CpeA and CpeB) and PE-II (MpeA and MpeB) subunits were computed using ProtParam Tools (Expasy, Gasteiger et al., 2005). Differences in the biochemical parameters of the $\alpha$ - and $\beta$-subunit sequences were tested using the non-parametric statistical test of Wilcoxon, and differences among clades were tested using Kruskal-Wallis test. Whether the observed substitutions were conservative or not was assessed using the MAFFT v7 software (Katoh and Standley, 2013). Physicochemical parameters of the PBP were retrieved using the ProtParam tool and the molecular flexibility was calculated with ProtScale (Gasteiger et al., 2005).

The crystal structure of Spirulina platensis PC (Padyana et al., 2001; PDB ID: 1HA7) was retrieved from the Protein Data Bank (Berman et al., 2003) and used as a template for modeling Synechococcus PC.
Structural protein models were generated using Phyre $^{2}$ (Kelley and Sternberg, 2009). The PCB and PEB structures were retrieved from Polysiphonia urceolata (Jiang et al., 2001; PDB ID: 1F99). Models were then visualized and aligned using PyMOL $\mathrm{v}$ 1.7.4. Synechococcus PC models were superimposed and the PC structural differences related to amino-acid substitutions were compared between cold- and warm-environment strains.

\section{Results and discussion}

\section{Marine Synechococcus PBS function optimally in specific thermal ranges}

The six Synechococcus strains were isolated from different latitudes and thermal niches (Figure 1). The temperature range for growth and preferenda of five of them were characterized in a previous study, whereas those of a sixth one isolated from the Red Sea, RS9907, is reported here (Table 1). Their markedly distinct temperature tolerance ranges as well as the $10^{\circ} \mathrm{C}$ difference in optimal growth temperature between tropical (RS9907 and M16.1) and subpolar strains (MVIR-16-2 and MVIR-18-1), clearly indicate that these strains correspond to distinct thermotypes (Pittera et al., 2014).

All strains were submitted to a stepwise temperature increase and their in vivo fluorescence emission spectra were recorded at each step. During the light-harvesting process, the distal PBP discs transfer the light-excitation energy to the proximal ones, which in turn transfer it to the PBS core. A low efficiency of energy transfer between two PBPs directly results in an increase in the fluorescence emitted by the donor PBP, at a specific wavelength. Thus, in vivo fluorescence emission spectra reflect the energy transfer efficiency along the PBS rod down to the reaction center II, and therefore the overall coupling of the PBS components. As expected from a number of previous studies (Six et al., 2004, 2005, 2007b; Bailey and Grossman, 2008), the fluorescence emission spectra typically exhibited three maxima, attributable to PE (565-575 nm), PC (650 nm) and the combined signal from allophycocyanin and RC chlorophylls, altogether called the PBS terminal acceptor (TA; $680 \mathrm{~nm}$; Figures 2a and b). We used the PE:PC emission fluorescence ratio as a parameter integrating the variations of the fluorescence emitted by the rod PBPs. This therefore allowed us to indirectly monitor the excitation energy transfer within the PBS rods (Ke, 2001; Six et al., 2007a).

PBS performance was strongly affected by the temperature increase and the progressive alteration followed the same succession of steps in all Synechococcus temperature ecotypes. The first temperature increments (from 22 to $28-31^{\circ} \mathrm{C}$, depending on strains) induced no significant change in the PE: PC emission ratio, showing that the energy was still efficiently transferred along the rod (Figure 2). As 


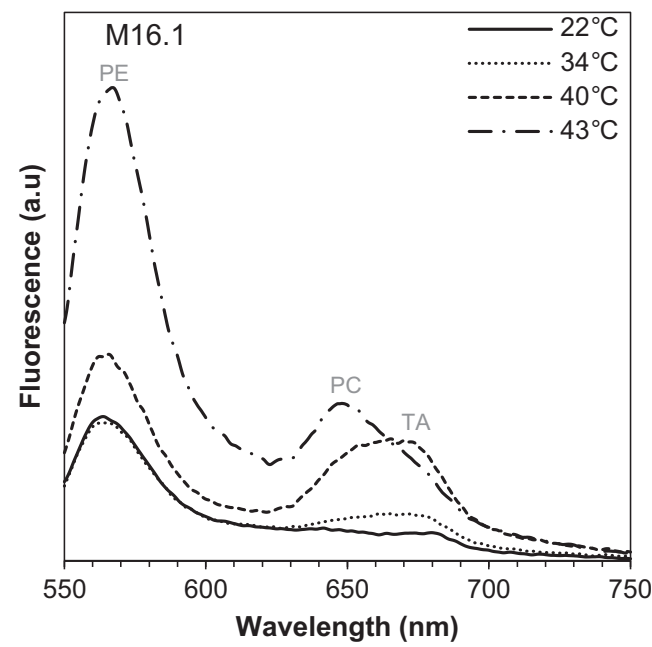

C

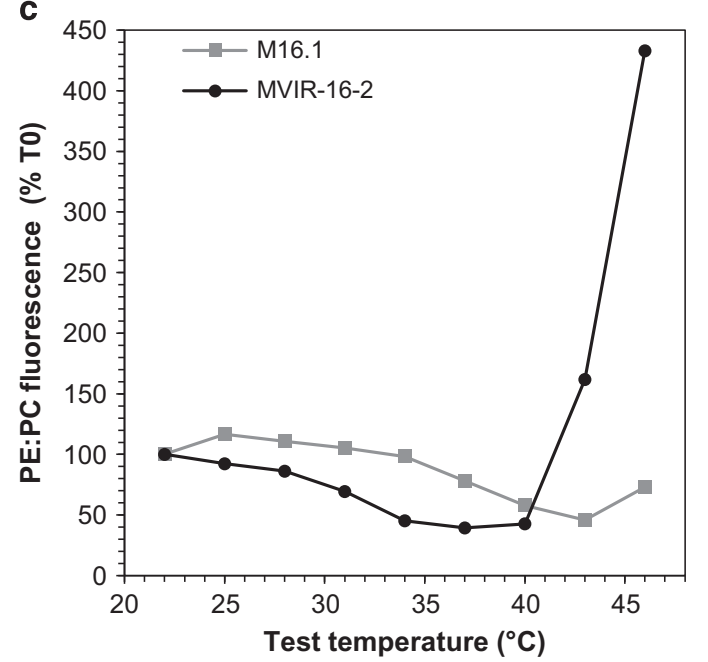

b

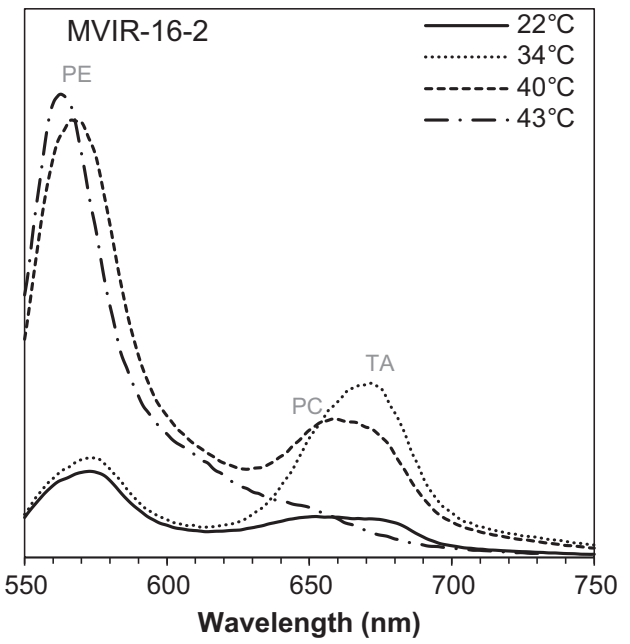

d

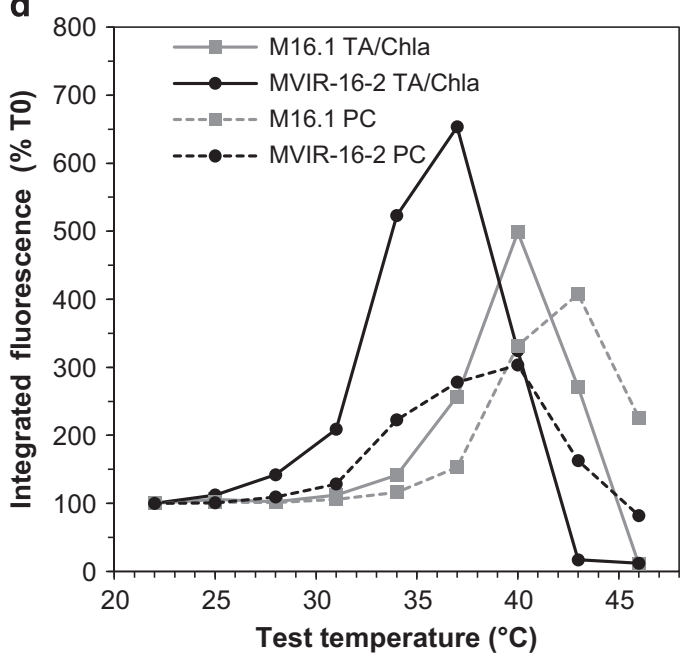

Figure 2 Examples of variations of the fluorescence emission spectra (with excitation at $530 \mathrm{~nm}$ ) for the tropical Synechococcus strain M16.1 and the subpolar strain MVIR-16-2 acclimated at $22^{\circ} \mathrm{C}$ and submitted to a progressive temperature increase. Fluorescence emission spectra of M16.1 (a) and MVIR-16-2 (b) strains at different temperatures. (c) Variations of the PE:PC (570:650 nm) fluorescence emission ratio during the course of temperature increase in both strains, expressed as percentage of the initial value (at $22{ }^{\circ} \mathrm{C}$ ). (d) Relative variations of fluorescence intensity expressed as percentage of the initial fluorescence value, after spectral decomposition of the two red components: phycocyanin at $650 \mathrm{~nm}$ (dashed line) and terminal acceptor at $680 \mathrm{~nm}$ (solid line). Note that the APC fluorescence component of the $680 \mathrm{~nm}$ peak cannot be easily separated from that of RC chlorophylls in decomposed spectra but it is expected to be much lower.

temperature kept increasing, fluorescence first increased in the red region $(650-680 \mathrm{~nm})$, leading to a decrease of the PE:PC ratio (Figures 2a-c). To identify which component between PC and TA first underwent this energy leak, we carried out a spectral decomposition of the fluorescence emission spectra (Figure 2d). Results showed that the first alterations occurred at the TA level $(680 \mathrm{~nm})$ and this energy leak likely mostly originated from chlorophylls bound to the reaction center II, consistently with a previous report that showed that heat induces a strong chl a fluorescence increase in Synechocystis sp. PCC 6803 (Inoue et al., 2001). The reaction center II is indeed known to be highly sensitive to increases in temperature, which notably causes the oxygenevolving complex to lose two out of the four
$\mathrm{Mn}$ atoms of the $\mathrm{Mn}_{4} \mathrm{CaO}_{5}$ cluster, a dissociation resulting in the breakdown of oxygen evolution (Kimura et al., 2002).

Spectral decompositions further showed that the PC fluorescence component $(650 \mathrm{~nm})$ also increased but at a higher temperature than the reaction center one (Figure 2d), leading the PE:PC ratio to keep on decreasing as temperature increased (Figure 2c). This indicates that the reaction center heat-induced disturbance then propagated to the base of the PBS rod, likely through allophycocyanin. This energetic jamming between the reaction center and the base of the PBS, which at this stage was still reversible, eventually destabilized the whole complex and ultimately led to the dismantling of the PBS. The latter process occurred abruptly and was 
recognizable by the sudden and large increase in fluorescence at $\sim 570 \mathrm{~nm}$ that indicated the release of free, highly fluorescing PEs in the cytosol (Figures 2a and b). At this stage, the PBS was irreversibly broken down and light harvesting was no longer possible. This PBS-dismantling phenomenon has been characterized in detail at the transcriptomic, proteomic and biophysical levels in several previous studies (Lao and Glazer, 1996; Sah et al., 1998; Six et al., 2007a; Pittera et al., 2014).

By applying an Arrhenius-type analysis (Supplementary Figure S1), it was possible to determine accurately the temperature at which the PBS dismantling occurred, $T_{\mathrm{PBS}}$, which we used as an indicator of the functional PBS thermostability in in vivo conditions. This parameter may thus provide information on the thermal plasticity of the lightharvesting function among strains. The comparison of the six strains grown at different temperatures showed that, in most cases, $T_{\mathrm{PBS}}$ increased with acclimation temperature until reaching a plateau (Figure 3). The apparent enhanced stability of PBS observed for strains grown at high temperature is most likely due to an increase in the thermotolerance of the reaction center itself, from where the disturbance originates (Inoue et al., 2001; Nishiyama et al., 2006). Temperature-induced variations of reaction center thermostability are thought to result from the capability of PsbU and PsbV proteins to stabilize the oxygen-evolving complex (Nishiyama et al., 1997; Yamasaki et al., 2002) and/or from adjustments of the fluidity of thylakoid membranes where the PS-II is embedded (Inoue et al., 2001; Loll et al., 2007). The reaction center thermoacclimation could also be modulated by changes in the D1 protein isoform from D1.1 to the more stable D1.2 (Kós et al., 2008). The difference in the amplitude of the increase of $T_{\mathrm{PBS}}$ in strains M16.1 and ROS8604 (Figures 3a and d) could thus originate in a different PS-II composition or in different capacities to induce such processes.
The plateau reached by the $T_{\mathrm{PBS}}$ parameter was variable and appeared to be related to the thermal niche of the marine Synechococcus strains (Figure 3). Indeed, strains isolated from subtropical (M16.1 and RS9907) or warm temperate waters (WH7803) displayed $T_{\mathrm{PBS}}$ values ranging from $35^{\circ} \mathrm{C}$ to $43^{\circ} \mathrm{C}$, whereas the clade I strains isolated from cold temperate and subpolar waters showed significantly lower values between $29^{\circ} \mathrm{C}$ and $39^{\circ} \mathrm{C}$ (Wilcoxson's test, $W=81, P$-value $<0.01$ ). These results show that the PBSs of high latitude strains are functionally less thermostable than the PBSs of low latitude ones, and therefore suggest that these light-harvesting complexes exhibit different levels of molecular flexibility. The different thermotypes of marine Synechococcus thus use PBSs that are functionally constrained by temperature.

Differences in PBS molecular flexibility among strains can be explained by differences in molecular flexibility of individual $P B P$

In the six marine Synechococcus strains studied here, PBS rods are made of three classes of hexameric PBPs, namely PC, PE-I and PE-II, which bind different sets of chromophores and are maintained together thanks to specific linker polypeptides (Ong and Glazer, 1991; Six et al., 2005; Six et al., 2007b). To understand whether the differences in PBS thermostability among strains are related to differences in the thermostability of individual PBPs, we first purified all rod PBPs in their native state, devoid of linker polypeptides. The six strains possess PBPs with identical optical properties, typical of Synechococcus pigment type 3a (Six et al., 2007b), that is, a PC binding two PEB and one PCB molecule (so-called R-PC-II; Ong and Glazer, 1987), a PE-I-bearing only PEB, and a PE-II binding one PUB and five PEB molecules (Supplementary Figure S2; Ong and Glazer, 1991). The PC, PE-I and PE-II, displayed fluorescence
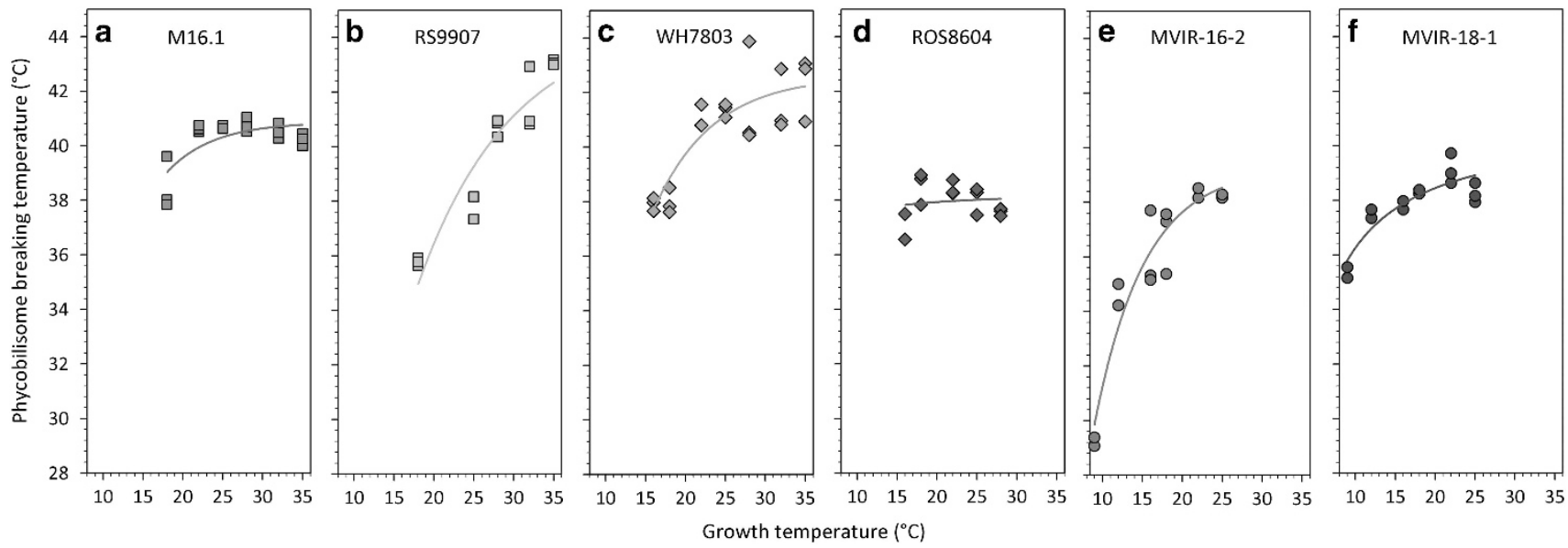

Figure 3 Phycobilisome-breaking temperature as a function of growth temperature for the six tested marine Synechococcus strains: M16.1 (a), RS9907 (b), WH7803 (c), ROS8604 (d), MVIR-16-2 (e), MVIR-18-1 (f). Three replicates are shown. Tropical strains are represented by squares, temperate ones by diamonds and subpolar strains by circles. 
emission maxima at 635,569 and $562 \mathrm{~nm}$, respectively. We then performed thermal unfolding curves for each of these 18 purified PBPs, in order to determine their mid-unfolding temperatures, $\mathrm{T}_{50 \%}$, a commonly used proxy for assessing and comparing the thermostability and molecular flexibility of proteins (Supplementary Figures S2 and S3; Jaenicke, 1991; Grimsley et al., 2013).

Upon temperature increase, all PBPs underwent a progressive drop of absorbance following a sigmoid curve (Supplementary Figure S3), down to levels lower than $10 \%$ of the initial value, and at $85^{\circ} \mathrm{C}$ proteins were completely unfolded and denatured. Fluorescence also decreased until complete quenching, following a quasi-linear function (Supplementary Figure S4). The comparative analysis of midunfolding temperatures for the three rod PBP types revealed two remarkable trends (Figure 4). First, the different classes of PBPs showed significantly distinct thermostability (Kruskal-Wallis, $\chi^{2}=37.11$, $d f=2, P$-value $<0.01)$. Indeed, on average, PE-II lost half of its absorption capacity at $60.9 \pm 2.6^{\circ} \mathrm{C}$, whereas the mean mid-unfolding temperature was $56.0 \pm 2.5^{\circ} \mathrm{C}$ and $51.8 \pm 2.0^{\circ} \mathrm{C}$ for PE-I and PC, respectively. These results indicate that PBP thermostability decreases toward the core of the PBS rod, with the most distal PE-II being the most stable PBP and PC the least. The latter finding is quite consistent with our observation that when cells undergo a moderate temperature shock, PC is the first rod PBP to show energetic disturbance in the PBS (Figure 2). As concerns PE-II, it is known to be released in the cytosol under excess light, ultraviolet or temperature stress conditions (Six et al., 2004; Six et al., 2007a; Pittera et al., 2014), during which it may constitute a soluble screen dissipating excess excitation energy as fluorescence, a role that likely requires molecular stability. Second, subtropical strains use PBPs that are significantly more thermostable than strains isolated from cold waters (Figure 4). Whereas the southernmost strains M16.1 and RS9907 displayed PE-II, PE-I and PC $\mathrm{T}_{50 \%}$ of $63.3 \pm 1.2^{\circ} \mathrm{C}, 58.4 \pm 0.7^{\circ} \mathrm{C}$ and $54.0 \pm 1.0^{\circ} \mathrm{C}$, respectively, this parameter was $5{ }^{\circ} \mathrm{C}$ lower for the northernmost strains MVIR-16-2 and MVIR-18-1, with corresponding values of $57.8 \pm 0.4{ }^{\circ} \mathrm{C}, 53.4 \pm 1.5^{\circ} \mathrm{C}$ and $49.6 \pm 0.4^{\circ} \mathrm{C}$ (Student's $t$-test: $t=9.68,7.49$ and 10.15 for PC, PE-I and PE-II, respectively; all $P$-values $<0.01)$. Consistently, midunfolding temperatures were strongly correlated to the latitude of strain isolation sites (Supplementary Figure S5). This indicates that the observed differences in overall PBS functional stability among strains isolated from distinct thermal niches rely at least in part on the differential thermostability of their constituting PBPs. The distinct thermal unfolding properties of PBPs strongly suggest that the molecular flexibility of these proteins differs. It is worth noting that the latter experiments were carried out on PBPs devoid of linker polypeptides, a lack that may somewhat modulate the thermotolerance of these molecules. Yet, the mid-unfolding temperature

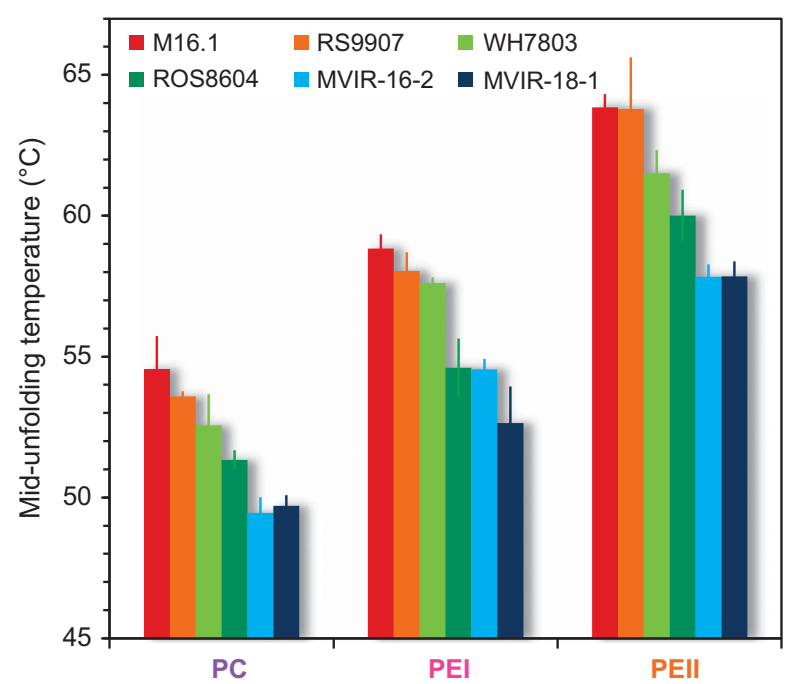

Figure 4 Mid-unfolding temperature of the three PBP of the six marine Synechococcus strains, derived from the thermal unfolding curves (see Supplementary Figures S2 and S3). Error bars are s.d. from the mean based on at least three replicates.

values reported here are quite in the range of previously reported values for other PBPs (Edwards et al., 1997; Patel et al., 2004; Pumas et al., 2011; Chaiklahan et al., 2012; Pumas et al., 2012).

To our knowledge, the high latitude Synechococcus ecotypes studied here possess the least thermostable rod PBPs described so far. Indeed, most previous studies have focused on PBPs extracted from thermophilic organisms isolated from hot springs, an environment in which these complexes require a particularly high thermostability (Edwards et al., 1997; Adir et al., 2001; Munier et al., 2014). Our study therefore shows that the diversification of PBP variants among PBP-containing organisms has occurred not only in specific extreme thermal niches, such as hot springs, but also along latitudinal gradients of seawater temperature.

Marine Synechococcus PCs exhibit molecular characteristics specific of the thermotypes

In order to unveil possible differences in the molecular conformation of PBSs resulting from adaption to the low temperature niche, as described for other proteins (Závodszky et al., 1998; Croce and van Amerongen, 2014), we analyzed 62 PBP subunit sequences from 21 Synechococcus strains belonging to clades adapted either to cold (I and IV) or warm environments (II and III; Supplementary Table S1). Amino-acid sequence identity was higher than $80 \%$ among MpeA, MpeB, CpeA, RpcA and RpcB, and 70\% among CpeB. Analyses of the PBP $\alpha-$ and $\beta$-subunits sequences showed that they exhibit a number of conserved characteristics. First, the aliphatic index of PBP $\alpha$-subunits (RpcA, CpeA and MpeA) is always lower than that of their $\beta$-subunit counterparts (Supplementary Table S2). This proxy for the relative volume occupied by aliphatic side chains was shown 
to be significantly higher in thermostable proteins (Závodszky et al., 1998; Jollivet et al., 2012). The grand average hydropathy index (GRAVY) is also different between the two PBP subunits, with $\alpha$ - being less hydrophobic than $\beta$-subunits (Table 2). Consistently, $\alpha$-subunits always contain a lower percentage of hydrophobic amino acids than their $\beta$ counterparts. Thus, even though $\alpha$-subunits exhibit a higher content of charged residues than $\beta$-subunits (Dill, 1990; Ladbury et al., 1995), $\alpha$-subunits globally appear as the least stable of the two subunits and the most vulnerable to unfolding factors, such as high temperature, and it thus may constitute a fragility point within PBP aggregates.

Protein molecular adaptations to temperature are known to be in part based on specific substitutions of amino acids, with glycine, serine, lysine and asparagine in mesophiles, generally replaced in thermophiles by alanine, threonine, arginine and glutamate, respectively (Argos et al., 1979; Szilagyi and Zavodszky, 2000; Fields, 2001). Extensive comparisons of the amino-acid content of each PBP polypeptide revealed that RpcA sequences from members of the warm-environment clade II had a significantly higher content in alanine than their counterparts from cold clade I strains, that is, $16.73 \pm 0.36 \%$ and $15.06 \pm 0.55 \%$, respectively (Kruskal-Wallis, $\chi^{2}=9.83, \quad d f=3, \quad P$-value $\left.<0.05\right)$. This suggests that the observed differential PC thermal unfolding properties between the high and low latitude strains might partly arise from differences in alanine content. Indeed, alanine accumulation in proteins is thought to increase hydrophobicity and therefore to decrease molecular flexibility, notably because this amino acid is an excellent helix former (see, for example, Dalhus et al., 2002; Kumwenda et al., 2013).

In contrast to $\mathrm{PC}$, comparative analyses of $\mathrm{PE}$ sequences (CpeA, CpeB, MpeA and MpeB) did not point out any clear evidence of differential aminoacid composition that could be related to the differential thermostability of PEs from subtropical and subpolar strains, possibly because of the fact that $\mathrm{PE}$ genes have been subjected to recurrent lateral transfers during Synechococcus evolution (Six et al., 2007b; Everroad and Wood, 2012; Humily et al., 2014).

In order to further understand the possible conformational differences among PCs from different Synechococcus thermotypes, we compared structural homology models of these proteins. Despite a high overall conservation of the 3D structure of PCs among strains (root mean square deviation $<0.5$ ), we identified two semi-conservative substitutions that are specific to the cold-environment clades I and IV (Supplementary Figure S6). Both of them are located on an exposed domain of helix A (amino acids 35-45), which ensures the contact between $\alpha$ and $\beta$ subunits (Adir et al., 2006). The first substitution, located on the $\alpha-43$ residue, involves the permutation of alanine found in clades II, III and V to glycine in clades I and IV. Such a substitution was previously observed when comparing orthologous proteins of thermophilic vs mesophilic organisms (Szilagyi and Zavodszky, 2000). Indeed, glycine is thought to provide increased backbone conformational flexibility (Matthews et al., 1987). The prediction of protein flexibility allowed us to detect a clear difference in this specific region of the RpcA chains between cold and warm-environment strains (Figure 5).

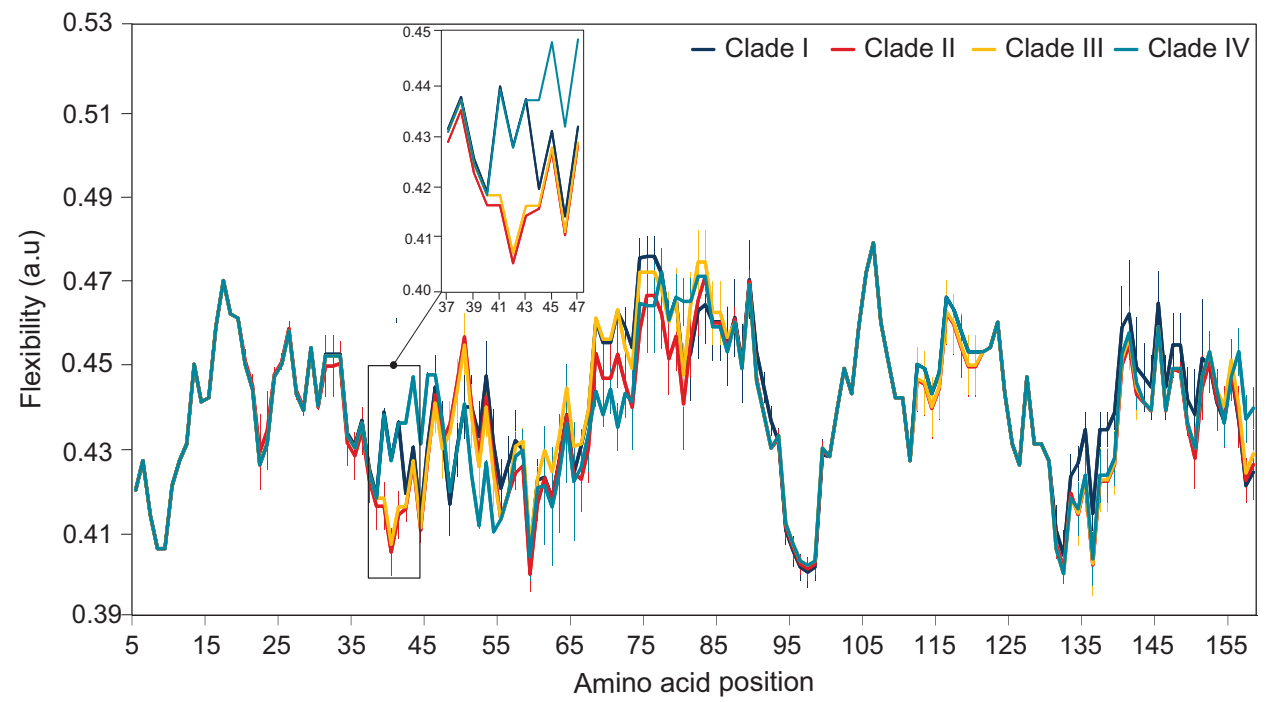

Figure 5 Predicted average flexibility along the amino-acid sequence of phycocyanin $\alpha$-subunit (RpcA) for Synechococcus strains of the cold-environment clades I and IV (dark blue, light blue, respectively), and the warm-environment clades II and III (orange and red, respectively). Error bars are calculated from the mean of 5, 9, 5 and 2 sequences for clades I, II, III and IV, respectively (see Supplementary Table S1). The amino-acid chain flexibility level was calculated using the Expasy tool ProtScale (Gasteiger et al., 2005). The insert shows the only major flexibility difference at the clade-specific substitution. 
Furthermore, the decrease in stability resulting from the substitution from alanine to glycine is thought to be stronger when it takes place within a helix (Menéndez-Arias and Argosf, 1989; Serrano et al., 1992). Alanine indeed consistently stabilizes helical conformations relatively to glycine, because it buries more polar areas upon folding and because its backbone entropy is lower. This substitution in RpcA might thus contribute to the lower stability of PC in the cold-environment Synechococcus clades I and IV compared with warm-environment clades II and III.
The second substitution is located on the $\beta-42$ residue and involves the replacement of a serine in cold-environment clades by an asparagine in warmenvironment clades (Figure 6). As this residue is located on helix A, it likely also participates to the stability of the aggregation between the PC $\alpha$ - and $\beta$-subunits in the whole $\alpha \beta$ hexameric aggregate. Furthermore, the structural modeling showed that this residue is located in the close vicinity of the $D$ cycle of the PEB chromophore bound to the cysteinyl residue $\beta-152$. It is likely that the side chain difference between the asparagine in cold clades

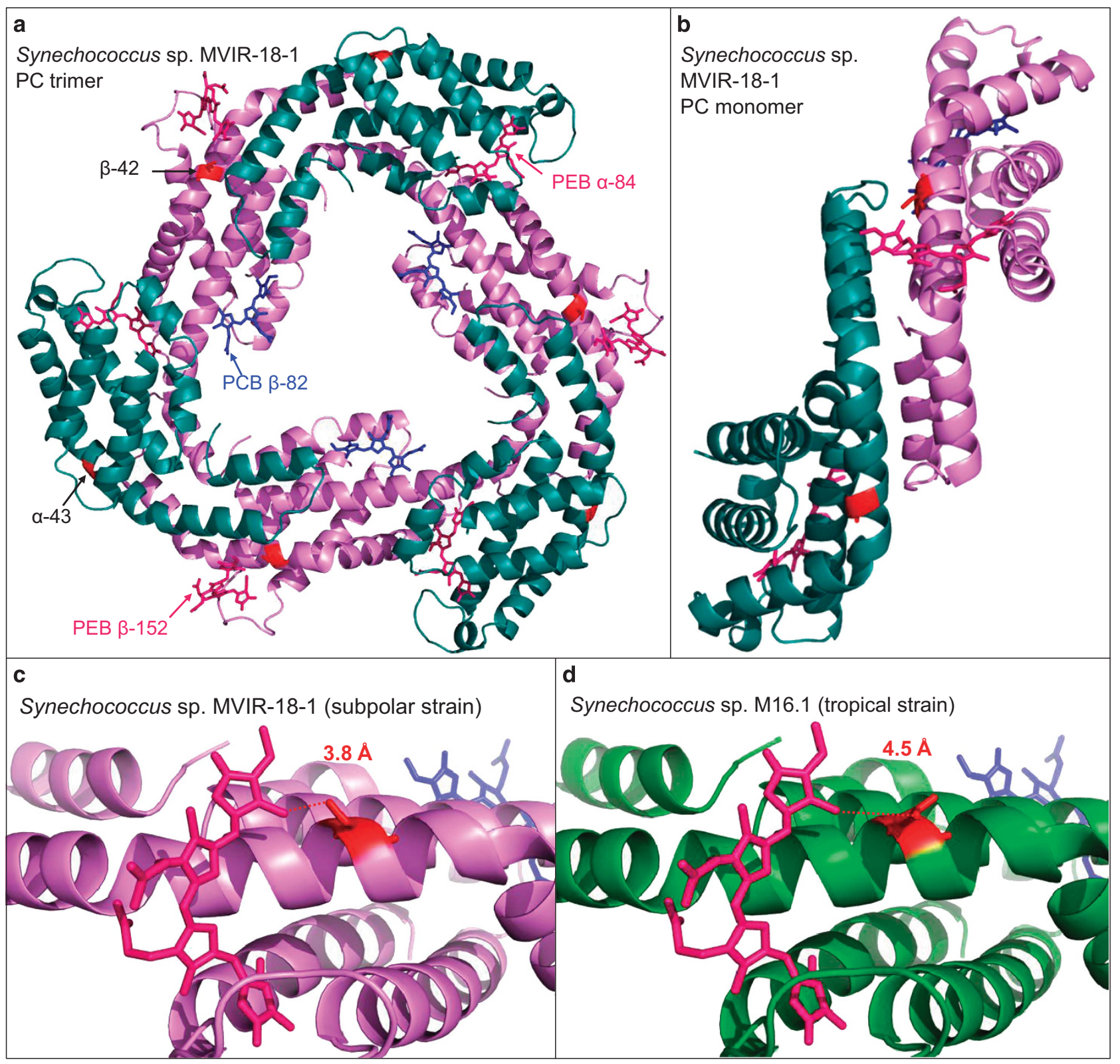

Figure 6 Computational homology model of an R-phycocyanin-II (R-PC-II) trimer structure of the subpolar strain Synechococcus sp. MVIR-18-1 and structural differences with the subtropical strain M16.1 R-PC-II. (a) Upper view of the R-PC-II trimer with $\alpha$-subunits (RpcA) in blue and $\beta$-subunits (RpcB) in pink. On each subunit, the amino-acid substitutions-specific to cold-environment clades, located at $\alpha-43$ and $\beta-42$, are shown in red. Phycoerythrobilins (PEB) are shown in dark pink and phycocyanobilins (PCB) in blue. (b) Side view of a PC monomer, showing the location of the substitution sites on helix A, involved in the $\alpha-\beta$ subunit interaction in Synechococcus sp. MVIR-18-1. (c) Zoom in the $\beta-42$ substitution with the subpolar strain Synechococcus sp. MVIR-18-1 displaying a serine and the subtropical Synechococcus sp. M16.1 displaying an asparagine (d). 
and the serine in warm ones influences the molecular stability of the planar conformation of the chromophore and therefore its absorption properties. In particular, this substitution is expected to decrease the steric hindrance and might lead to an increase in flexibility of the polypeptide chain. It is also important to note that, in such complex protein assemblages, the two abovementioned substitutions are repeated six times each, resulting in a summation effect that may greatly impact the overall protein properties.

\section{Conclusion}

Comparative analyses of the photosynthetic antenna complexes of six different marine Synechococcus strains isolated from different latitudes revealed clade-specific adaptations to temperature that are likely critical to maintain the biophysical properties of these pigment-protein complexes in the specific thermal niches of these strains. This result nicely complements previous work (Pittera et al., 2014), which showed that the sensitivity of the lightharvesting process to temperature variations was thermotype-dependent and that the thermoresistance of PBS complexes was directly associated with the growth capacities of the considered strain. Altogether, these complementary studies suggest that the thermoadaptability of light-harvesting complexes likely has a key role in the distinct latitudinal distribution of thermotypes (Sohm et al., 2015; Farrant et al., 2016), although other factors are certainly also involved, such as different membrane composition adjustments or of heat shock proteins and/or antifreeze metabolites.

The functional differences between PBSs of cold- and warm-environment strains are seemingly due to large differences in the molecular flexibility of the three PBPs constituting the rods. In vivo temperature-response curves indicated that PC is the first rod PBP to undergo energetic decoupling, which then propagates through the entire rod, until complete dismantling of the PBS complex. Consistently, we show that among the three rod PBPs, PC is the least thermostable and probably constitutes a fragility point of the PBS rod under heat stress. Our results suggest that the thermotypespecific differences in the stability or flexibility of PC originate at least in part from the modulation of the alanine content as well as from two amino-acid substitutions. We hypothesize that temperature has exerted significant adaptive pressure on PBP evolution in marine Synechococcus, conferring a fitness advantage to cold-adapted strains at high latitude, as shown by their specific ability to grow and photosynthesize at low temperature (Pittera et al., 2014). Further evidence for the central role of the trade-off between PBP flexibility and stability for adaptation to cold and warm niches, respectively, could be obtained from directed mutagenesis targeting the amino acids that we found to differ between the PCs of cold and warm thermotypes. Yet, such genetic manipulation remains a challenging task in marine picocyanobacteria.

In many organisms, including marine picocyanobacteria (Moore et al., 1995; Johnson et al., 2006; Pittera et al., 2014), the maximal growth-rate temperature is very close to the cell death temperature and physiological models suggest that the latter temperature coincides with a denaturation catastrophe of the proteome (Dill et al., 2011). The high sensitivity of protein structure and function to temperature variations indicates that the ongoing global climate change is likely to affect cells through perturbation of enzymatic and structural proteins. The evolutionary process described here, which is a component of the thermotypic diversification occurring in several major Synechococcus lineages, is probably one of the key factors explaining the global ecological success of these cyanobacteria. Elucidating such processes is important in the context of global climate change as the latter will undoubtedly induce alterations of the composition of the phytoplanktonic communities over large oceanic spatial scales and thus impact top levels of food webs.

\section{Conflict of Interest}

The authors declare no conflict of interest.

\section{Acknowledgements}

This work was funded by the French program ANR SAMOSA (ANR-13-ADAP-0010), EMBRC France (INFRA-2010-2.2.5) and the European Union programs MicroB3 and MaCuMBA (grant agreements 287589 and 311975, respectively). Justine Pittera was supported by the French Ministry of Higher Education and Research. We warmly thank Laurence Garczarek, Florian Humily and Morgane Ratin for providing us new phycobiliprotein sequences retrieved from unpublished genomes sequenced by the Genoscope (Evry, France) and assembled with the help of Gregory Farrant and the local bioinformatics platform (ABIMS, Roscoff, France). We warmly thank Mirjam Czjzek for the insightful discussion on protein structures. We are also grateful to the Roscoff Culture Collection for maintaining the Synechococcus strains used in this study and especially to Florence Legall who isolated some of them. We certify that there is no conflict of interest with any financial organization regarding the material presented in this manuscript.

\section{References}

Adir N, Dobrovetsky Y, Lerner N. (2001). Structure of C-phycocyanin from the thermophilic cyanobacterium Synechococcus vulcanus at $2.5 \AA$ A structural implications for thermal stability in phycobilisome assembly. J Mol Biol 313: 71-81. 
Adir N, Dines M, Klartag M, McGregor A, Melamed-Frank M. (2006). Assembly and disassembly of phycobilisomes. In: Shively J (ed). Complex intracellular structures in prokaryotes. Springer-Verlag: Berlin Heidelberg, Germany, pp 47-77.

Ahlgren N, Rocap G. (2012). Diversity and distribution of marine Synechococcus: multiple gene phylogenies for consensus classification and development of qPCR assays for sensitive measurement of clades in the ocean. Front Microbiol 3: 213.

Argos P, Rossmann M, Grau U, Zuber H, Frank G, Tratschin J. (1979). Thermal stability and protein structure. Biochemistry 18: 5698-5703.

Bailey S, Grossman A. (2008). Photoprotection in cyanobacteria: regulation of light harvesting. Photochem Photobiol 84: 1410-1420.

Behrenfeld M, O’Malley R, Siegel D, McClain C, Sarmiento J, Feldman $\mathrm{G}$ et al. (2006). Climate-driven trends in contemporary ocean productivity. Nature 444: 752-755.

Berman H, Henrick K, Nakamura H. (2003). Announcing the worldwide Protein Data Bank. Nat Struct Mol Biol 10: 980.

Blot N, Wu X, Thomas J-C, Zhang J, Garczarek L, Böhm S et al. (2009). Phycourobilin in trichromatic phycocyanin from oceanic cyanobacteria is formed post-translationally by a phycoerythrobilin lyase-isomerase. J Biol Chem 284: 9290-9298.

Bowen R, Hartung R, Gindt Y. (2000). A simple protein purification and folding experiment for general chemistry laboratory. J Chem Educ 77: 1456.

Chaiklahan R, Chirasuwan N, Bunnag B. (2012). Stability of phycocyanin extracted from Spirulina sp.: influence of temperature, $\mathrm{pH}$ and preservatives. Process Biochem 47: 659-664.

Croce R, van Amerongen H. (2014). Natural strategies for photosynthetic light harvesting. Nat Chem Biol 10: 492-501.

Dahlhoff E, O'Brien J, Somero G, Vetter R. (1991). Temperature effects on mitochondria from hydrothermal vent invertebrates: Evidence for adaptation to elevated and variable habitat temperatures. Physiol Zool 64: 1490-1508.

Dalhus B, Saarinen M, Sauer U, Eklund P, Johansson K, Karlsson A et al. (2002). Structural basis for thermophilic protein stability: Structures of thermophilic and mesophilic malate dehydrogenases. J Mol Biol 318: 707-721.

Dill K. (1990). Dominant forces in protein folding. Biochemistry 29: 7133-7155.

Dill K, Ghosh K, Schmit J. (2011). Physical limits of cells and proteomes. Proc Natl Acad Sci USA 108: 17876-17882.

Edwards M, Hauer C, Stack R, Eisele L, MacColl R. (1997). Thermophilic C-phycocyanin: effect of temperature, monomer stability, and structure. Biochim Biophys Acta 1321: 157-164.

Everroad R, Wood A. (2012). Phycoerythrin evolution and diversification of spectral phenotype in marine Synechococcus and related picocyanobacteria. Mol Phylogen Evol 64: 381-392.

Falkowski P. (1994). The role of phytoplankton photosynthesis in global biochemical cycles. Photosynth Res 39: $235-258$.

Farrant G, Doré D, Cornejo-Castillo F, Partensky F, Ratin M, Ostrowski M et al. (2016). Delineating ecologically significant taxonomic units from global patterns of marine picocyanobacteria. Proc Nat Acad Sci USA 113: E3365-E3374.
Fields P. (2001). Review: protein function at thermal extremes: balancing stability and flexibility. Comp Biochem Physiol Pt A 129: 417-431.

Flombaum P, Gallegos J, Gordillo R, Rincón J, Zabala L, Jiao $\mathrm{N}$ et al. (2013). Present and future global distributions of the marine cyanobacteria Prochlorococcus and Synechococcus. Proc Natl Acad Sci USA 110: 9824-9829.

Fuller NJ, Marie D, Partensky F, Vaulot D, Post A, Scanlan D. (2003). Clade-specific 16S ribosomal DNA oligonucleotides reveal the predominance of a single marine Synechococcus clade throughout a stratified water column in the Red Sea. Appl Environ Microbiol 69: $2430-2443$.

Gasteiger E, Hoogland C, Gattiker A, Duvaud S, Wilkins M, Appel $\mathrm{R}$ et al. (2005). Protein identification and analysis tools on the ExPASy Server. In: Walker J (ed). The Proteomics Protocols Handbook. Humana Press: Totowa, NJ, USA, pp 571-607.

Glazer A, Fang S, Brown D. (1973). Spectroscopic properties of C-phycocyanin and of its $\alpha$ and $\beta$ subunits. J Biol Chem 248: 5679-5685.

Glazer A, Hixson C. (1975). Characterization of R-phycocyanin. Chromophore content of R-phycocyanin and C-phycoerythrin. J Biol Chem 250: 5487-5495.

Glazer A, Hixson C. (1977). Subunit structure and chromophore composition of rhodophytan phycoerythrins. Porphyridium cruentum B-phycoerythrin and b-phycoerythrin. J Biol Chem 252: 32-42.

Glazer A. (1984). Phycobilisome a macromolecular complex optimized for light energy transfer. Biochim Biophys Acta 768: 29-51.

Glazer A. (1985). Light harvesting by phycobilisomes. Ann Rev Biophys Biophys Chem 14: 47-77.

Glazer A. (1989). Light guides. Directional energy transfer in a photosynthetic antenna. J Biol Chem 264: 1-4.

Grimsley G, Trevino S, Thurlkill R, Scholtz J. (2013). Determining the conformational stability of a protein from urea and thermal unfolding curves. Curr Prot Protein Sci Chapter 28: Unit 28.4.

Hall TA. (1999). BioEdit: a user-friendly biological sequence alignment editor and analysis program for Windows 95/98/NT. Nucleic Acids Symp Ser 41: 95-98.

Herdman M, Castenholz R, Waterbury J, Rippka R. (2001). Form-genus XIII. Synechococcus. In: Boone D, Castenholz R (eds). Bergey's Manual of Systematic Bacteriology, 2nd edn, Springer-Verlag: New York, NY, USA, pp 508-512.

Huang S, Wilhelm S, Harvey $H$, Taylor K, Jiao N, Chen F. (2012). Novel lineages of Prochlorococcus and Synechococcus in the global oceans. ISME J 6: 285-297.

Humily F, Partensky F, Six C, Farrant G, Ratin M, Marie D et al. (2013). A gene island with two possible configurations Is involved in chromatic acclimation in marine. Synechococcus. PLoS One 8: e84459.

Humily F, Farrant G, Marie D, Partensky F, Mazard S, Perennou $\mathrm{M}$ et al. (2014). Development of a targeted metagenomic approach to study a genomic region involved in light harvesting in marine Synechococcus. FEMS Microbiol Ecol 88: 231-249.

Inoue N, Taira Y, Emi T, Yamane Y, Kashino Y, Koike H et al. (2001). Acclimation to the growth temperature and the high-temperature effects on photosystem II and plasma membranes in a mesophilic cyanobacterium, Synechocystis sp PCC6803. Plant Cell Physiol 42: 1140-1148. 
Jaenicke R. (1991). Protein folding: local structures, domains, subunits, and assemblies. Biochemistry 30: 3147-3161.

Jaenicke R, Böhm G. (1998). The stability of proteins in extreme environments. Curr Opin Struct Biol 8: 738-748.

Jiang T, Zhang J-P, Chang W-R, Liang D-C. (2001). Crystal structure of R-phycocyanin and possible energy transfer pathways in the phycobilisome. Biophys $J$ 81: 1171-1179.

Johnson Z, Zinser E, Coe A, McNulty N, Woodward E, Chisholm S. (2006). Niche partitioning among Prochlorococcus ecotypes along ocean-scale environmental gradients. Science 311: 1737-1740.

Jollivet D, Mary J, Gagnière N, Tanguy A, Fontanillas E, Boutet I et al. (2012). Proteome adaptation to high temperatures in the ectothermic hydrothermal vent Pompeii worm. PLoS One 7: e31150.

Katoh K, Standley D. (2013). MAFFT Multiple sequence alignment software version 7: Improvements in performance and usability. Mol Biol Evol 30: 772-780.

Ke B. (2001). Phycobiliproteins and phycobilisomes. In: Ke B (ed). Photosynthesis: Photobiochemistry and photobiophysics. Kluwer Academic Publishers: Dordercht, pp 253-270.

Kelley L, Sternberg M. (2009). Protein structure prediction on the Web: a case study using the Phyre server. Nat Protoc 4: 363-371.

Kimura A, Eaton-Rye J, Morita E, Nishiyama Y, Hayashi H. (2002). Protection of the oxygen-evolving machinery by the extrinsic proteins of photosystem II is essential for development of cellular thermotolerance in Synechocystis sp. PCC 6803. Plant Cell Physiol 43: 932-938.

Kós P, Deák Z, Cheregi O, Vass I. (2008). Differential regulation of $p s b A$ and $p s b D$ gene expression, and the role of the different D1 protein copies in the cyanobacterium Thermosynechococcus elongatus BP-1. Biochim Biophys Acta 1777: 74-83.

Kumwenda B, Litthauer D, Bishop O, Reva O. (2013). Analysis of protein thermostability enhancing factors in industrially important Thermus bacteria species. Evol Bioinfo Online 9: 327-342.

Kupper H, Andresen E, Wiegert S, Simek M, Leitenmaier B, Setlik I. (2009). Reversible coupling of individual phycobiliprotein isoforms during state transitions in the cyanobacterium Trichodesmium analysed by single-cell fluorescence kinetic measurements. Biochim Biophys Acta 1787: 155-167.

Ladbury J, Lemmon M, Zhou M, Green J, Botfield M, Schlessinger J. (1995). Measurement of the binding of tyrosyl phosphopeptides to $\mathrm{SH} 2$ domains: a reappraisal. Proc Natl Acad Sci USA 92: 3199-3203.

Lao K, Glazer A. (1996). Ultraviolet-B photodestruction of a light-harvesting complex. Proc Natl Acad Sci USA 93: 5258-5263.

Loll B, Kern J, Saenger W, Zouni A, Biesiadka J. (2007). Lipids in photosystem II: Interactions with protein and cofactors. Biochim Biophys Acta 1767: 509-519.

MacColl R, Csatorday K, Berns D, Traeger E. (1980). Chromophore interactions in allophycocyanin. Biochemistry 19: 2817-2820.

Mackey K, Paytan A, Caldeira K, Grossman A, Moran D, McIlvin M et al. (2013). Effect of temperature on photosynthesis and growth in marine Synechococcus spp. Plant Physiol 163: 815-829.
Matthews B, Nicholson H, Becktel W. (1987). Enhanced protein thermostability from site-directed mutations that decrease the entropy of unfolding. Proc Natl Acad Sci USA 84: 6663-6667.

Mazard S, Ostrowski M, Partensky F, Scanlan D. (2012). Multi-locus sequence analysis, taxonomic resolution and biogeography of marine Synechococcus. Environ Microbiol 14: 372-386.

Mella-Flores D, Mazard S, Humily F, Partensky F, Mahé F, Bariat L et al. (2011). Is the distribution of Prochlorococcus and Synechococcus ecotypes affected by global warming? Biogeosciences 8: 2785-2804.

Menéndez-Arias L, Argosf P. (1989). Engineering protein thermal stability. J Mol Biol 206: 397-406.

Moore L, Goericke R, Chisholm S. (1995). Comparative physiology of Synechococcus and Prochlorococcus: influence of light and temperature on growth, pigments, fluorescence and absorptive properties. Mar Ecol Prog Ser 116: 259-275.

Munier M, Jubeau S, Wijaya A, Morançais M, Dumay J, Marchal L et al. (2014). Physicochemical factors affecting the stability of two pigments: R-phycoerythrin of Grateloupia turuturu and B-phycoerythrin of Porphyridium cruentum. Food Chem 150: 400-407.

Murata N, Takahashi S, Nishiyama Y, Allakhverdiev S. (2007). Photoinhibition of photosystem II under environmental stress. Biochim Biophys Acta 1767: 414-421.

Neuer S. (1992). Growth dynamics of marine Synechococcus spp. in the Gulf of Alaska. Mar Ecol Prog Ser 83: 251-262.

Nishiyama Y, Los D, Hayashi H, Murata N. (1997). Thermal Protection of the oxygen-evolving machinery by PsbU, an extrinsic protein of photosystem II, in Synechococcus sp PCC 7002. Plant Physiol 115: 1473-1480.

Nishiyama Y, Allakhverdiev S, Murata N. (2006). A new paradigm for the action of reactive oxygen species in the photoinhibition of photosystem II. Biochim Biophys Acta 1757: 742-749.

Ong L, Glazer A. (1987). R-phycocyanin II, a new phycocyanin occurring in marine Synechococcus species. Identification of the terminal energy acceptor bilin in phycocyanins. J Biol Chem 262: 6323-6327.

Ong L, Glazer A. (1991). Phycoerythins of marine unicellular cyanobacteria. 1. Bilin types and locations and energy-transfer pathways in Synechococcus spp. phycoerythrins. J Biol Chem 266: 9515-9527.

Padyana A, Bhat V, Madyastha K, Rajashankar K, Ramakumar S. (2001). Crystal structure of a lightharvesting protein C-phycocyanin from Spirulina platensis. Biochem Biophys Res Commun 282: 893-898.

Partensky F, Blanchot J, Vaulot D. (1999). Differential distribution and ecology of Prochlorococcus and Synechococcus in oceanic waters: a review. In: Charpy L, Larkum A (eds). Marine Cyanobacteria. Bull Instit Oceanogr, Monaco, Italy, 457-475.

Patel A, Pawar R, Mishra S, Sonawane S, Ghosh P. (2004). Kinetic studies on thermal denaturation of C-phycocyanin. Indian J Biochem Biophys 41: 254-257.

Pittera J, Humily F, Thorel M, Grulois D, Garczarek L, Six C. (2014). Connecting thermal physiology and latitudinal niche partitioning in marine Synechococcus. ISME J 8: 1221-1236.

Pumas C, Vacharapiyasophon P, Peerapornpisal Y, Leelapornpisid P, Boonchum W, Ishii M et al. (2011). 
Thermostablility of phycobiliproteins and antioxidant activity from four thermotolerant cyanobacteria. Phycol Res 59: 166-174.

Pumas C, Peerapornpisal Y, Vacharapiyasophon P, Leelapornpisid P, Boonchum W, Ishii M et al. (2012). Purification and characterization of a thermostable phycoerythrin from hot spring cyanobacterium Leptolyngbya sp. KC45. Int J Agric Biol 14: 121-125.

Rippka R, Coursin T, Hess W, Lichtlé C, Scanlan DJ, Palinska KA et al. (2000). Prochlorococcus marinus Chisholm et al. 1992 subsp. pastoris subsp. nov. strain PCC 9511, the first axenic chlorophyll a2/b2-containing cyanobacterium (Oxyphotobacteria). Int J Syst Evol Microbiol 50: 1833-1847.

Sah J, Krishna K, Srivastava M, Mohanty P. (1998). Effects of ultraviolet-B radiation on phycobilisomes of Synechococcus PCC 7942: alterations in conformation and energy transfer characteristics. IUBMB Life 44: 245-257.

Scheer H, Kufer W. (1977). Conformational studies on C-phycocyanin from Spirulina platensis. Z Naturforsch 32c: 513-519.

Serrano L, Sancho J, Hirshberg M, Fersht A. (1992). $\alpha$-Helix stability in proteins: I. Empirical correlations concerning substitution of side-chains at the $\mathrm{N}$ and C-caps and the replacement of alanine by glycine or serine at solvent-exposed surfaces. J Mol Biol 227: 544-559.

Sidler W. (1994). Phycobilisome and phycobiliprotein structures. In: Bryant D (ed). The Molecular Biology of Cyanobacteria. Kluwer Academic Publishers: Dordrecht, the Netherlands, pp 139-216.

Six C, Thomas J-C, Brahamsha B, Lemoine Y, Partensky F. (2004). Photophysiology of the marine cyanobacterium Synechococcus sp. WH8102, a new model organism. Aquat Microb Ecol 35: 17-29.

Six C, Thomas J-C, Thion L, Lemoine Y, Zal F, Partensky F. (2005). Two novel phycoerythrin-associated linker proteins in the marine cyanobacterium Synechococcus sp strain WH8102. J Bacteriol 187: 1685-1694.

Six C, Joubin L, Partensky F, Holtzendorff J, Garczarek L. (2007a). UV-induced phycobilisome dismantling in the marine picocyanobacterium Synechococcus sp. WH8102. Photosynth Res 92: 75-86.

Six C, Thomas J, Garczarek L, Ostrowski M, Dufresne A, Blot $\mathrm{N}$ et al. (2007b). Diversity and evolution of phycobilisomes in marine Synechococcus spp. - a comparative genomics study. Genome Biol 8: R259.

Sohm J, Ahlgren N, Thomson Z, Williams C, Moffett J, Saito M et al. (2015). Co-occurring Synechococcus ecotypes occupy four major oceanic regimes defined by temperature, macronutrients and iron. ISME J 10: 333-345.

Stillman J, Somero G. (1996). Adaptation to temperature stress and aerial exposure in congeneric species of intertidal porcelain crabs (genus Petrolisthes): correlation of physiology, biochemistry and morphology with vertical distribution. J Exp Biol 199: 1845-1855.

Szilagyi A, Zavodszky P. (2000). Structural differences between mesophilic, moderately thermophilic and extremely thermophilic protein subunits: results of a comprehensive survey. Structure 8: 493-504.

Wyman M. (1992). An in vivo method for the estimation of phycoerythrin concentrations in marine cyanobacteria (Synechococcus spp.). Limnol Oceanogr 37: 1300-1306.

Yamasaki T, Yamakawa T, Yamane Y, Koike H, Satoh K, Katoh S. (2002). Temperature acclimation of photosynthesis and related changes in photosystem II electron transport in winter wheat. Plant Physiol 128: 1087-1097.

Závodszky P, Kardos J, Svingor Á, Petsko G. (1998). Adjustment of conformational flexibility is a key event in the thermal adaptation of proteins. Proc Natl Acad Sci USA 95: 7406-7411.

Zinser E, Johnson Z, Coe A, Karaca E, Veneziano D, Chisholm S. (2007). Influence of light and temperature on Prochlorococcus ecotype distributions in the Atlantic Ocean. Limnol Oceanogr 52: 2205-2220.

Zwirglmaier K, Jardillier L, Ostrowski M, Mazard S, Garczarek L, Vaulot D et al. (2008). Global phylogeography of marine Synechococcus and Prochlorococcus reveals a distinct partitioning of lineages among oceanic biomes. Environ Microbiol 10: 147-161.

Supplementary Information accompanies this paper on The ISME Journal website (http://www.nature.com/ismej) 